\title{
Generation of an anti-EpCAM antibody and epigenetic regulation of EpCAM in colorectal cancer
}

\author{
MEI-YING LIAO ${ }^{1,2}$, MARK YEN-PING KUO ${ }^{1}$, TUNG-YING LU ${ }^{2}$, YI-PING WANG ${ }^{1,2}$ and HAN-CHUNG WU ${ }^{1-3}$ \\ ${ }^{1}$ Graduate Institute of Clinical Dentistry, School of Dentistry, National Taiwan University, Taipei; \\ ${ }^{2}$ Institute of Cellular and Organismic Biology, ${ }^{3}$ Genomics Research Center, Academia Sinica, Taipei 115, Taiwan, R.O.C.
}

Received November 11, 2014; Accepted January 15, 2015

DOI: 10.3892/ijo.2015.2876

\begin{abstract}
We have generated a novel monoclonal antibody (mAb), OCAb9-1, which specifically binds to various types of cancer cell lines, but not to normal cells. According to the results of immunoaffinity chromatography, LC-MS/MS analysis, co-immunoprecipitation, and RNA interference studies, the target protein of OCAb9-1 is the epithelial cell adhesion molecule (EpCAM). EpCAM is a type I transmembrane glycoprotein which is highly expressed in epithelial-transformed neoplasia and tumor-initiating cells (TICs). However, regulation of EPCAM gene expression in tumors and its role in tumorigenesis are not fully understood. In the present study, we show that EpCAM expression is elevated in several cancer cell lines and tumor tissues. Loss-of-function experiments were performed to demonstrate that EpCAM negatively regulates expression of p53 and p21, and promotes tumor cell growth, colony formation, migration and invasion. The median overall survival of tumor-bearing mice treated with OCAb9-1 was significantly higher than that of PBS-treated mice. Moreover, we report that the interplay between SUZ12 and JMJD3 results in dynamic regulation of lysine 27 trimethylation of histone 3 (H3K27me3). Taken together, our findings suggest that the anti-EpCAM mAb may be suitable for use in cancer diagnosis, prognosis, imaging and therapy. Furthermore, EpCAM overexpression in cancer cells is strongly associated with tumor progression, and may be regulated by epigenetic mechanisms.
\end{abstract}

\section{Introduction}

Colorectal cancer is one of the most common cancers worldwide, with over 1.2 million new cancer cases and 608,700 related deaths reported worldwide $(1,2)$. One contributing factor appears to be high expression levels of the cell surface protein EpCAM, which correlate with increased tumorigenesis

Correspondence to: Dr Han-Chung Wu, Institute of Cellular and Organismic Biology, Academia Sinica, 128 Academia Road, Section 2, Nankang, Taipei 11529, Taiwan, R.O.C.

E-mail: hcw0928@gate.sinica.edu.tw

Key words: EpCAM, colorectal carcinoma, monoclonal antibody, epigenetic regulation in a range of carcinomas, including breast, colon, and head and neck squamous cell carcinoma (HNSCC) $(3,4)$. Therefore, we have been investigating the biological function, gene regulation and clinicopathological significance of this protein.

EpCAM (CD326) is a homophilic, calcium-independent cell adhesion molecule (a type I transmembrane glycoprotein) of 39-42 kDa, encoded by the TACSTDl gene on the long arm of chromosome 2p21 $(5,6)$. Overexpression of EpCAM in epithelial cancers is associated with enhanced proliferation and malignant potential $(7,8)$, and levels of EpCAM expression are correlated with de-differentiation and malignant proliferation of epithelial cells $(9,10)$. Moreover, EpCAM is frequently detected in cancer-initiating cells $(11,12)$ and normal stem or progenitor cells (13-17). As it is often highly expressed in cancer cells, EpCAM has gained attention as a potential target for diagnostic and antibody-based immunotherapies for a spectrum of malignancies (18-23).

Most colorectal cancer cases (75-80\%) occur sporadically as a result of the accumulation of both mutations and epigenetic modifications of several genes (24). One of the most studied epigenetic markers in colorectal cancer is DNA methylation, which involves covalent addition of methyl groups to the $5^{\prime}$ position of cytosine residues, usually at cytosine-phosphateguanine $(\mathrm{CpG})$ dinucleotides (25). Over the last few years, much has been learned about the effects of DNA methylation and histone modifications on the regulation of gene expression and genome function. Several studies have reported on the DNA methylation status of the EpCAM promoter in lung, colon, prostate, liver, bladder, ovary and breast cancer cells and tissues (26-29). For various tumor types, EpCAM overexpression is associated with DNA hypomethylation of the promoter; furthermore, treatment of EpCAM-negative cells with a DNA methylation inhibitor induced EpCAM expression $(26,27,30)$.

The ever-increasing number of genes reported to exhibit epigenetic alterations in cancer emphasizes the importance of these modifications for future diagnosis, prognosis, and prediction of response to therapies (31). Therefore, research is currently ongoing to develop rapid, cost effective and reproducible tools for the detection of epigenetic markers (31). In the present study, we investigated epigenetic mechanisms underlying the overexpression of EpCAM in colon cancer. A better understanding of the regulation of EpCAM gene expression may provide new opportunities for cancer therapy, based on reversing epigenetic markers. 
To clarify the biological significance of EpCAM in tumor progression, we examined EpCAM expression in a series of cancer cell lines and tumor tissues. In addition, we addressed whether epigenetic transitions in the 5' flanking region of the EpCAM promoter are responsible for altered expression in colorectal cancer cells, by evaluating $\mathrm{CpG}$ status using methylation-specific PCR (MSP) and bisulfite sequencing, and histone modification by chromatin immunoprecipitation (ChIP). Our data suggest that epigenetic upregulation of EpCAM may contribute to tumor progression.

\section{Materials and methods}

Cell lines and culture. The following human cell lines were used: oral cancer (SAS), nasopharyngeal carcinoma (NPC) (32), ovarian cancer cell line SKOV-3 (ATCC, Manassas, VA, USA; HTB-77), colorectal cancer cell line HCT116 (ATCC: CCL-247), COLON 205 (ATCC: CCL-222), SW620 (ATCC: CCL-227), lung cancer cell line H441 (ATCC: HTB-174) or H520 (ATCC: HTB-182), breast cancer cell line MCF7 (ATCC: HTB-22), pancreatic cancer cell line BxPC-3 (ATCC: CRL-1687) or MIA PaCa-2 (ATCC: CRL-1420), Mahlavu (33), Prostate adenocarcinoma cell line PC-3 (ATCC: CRL-1435), kidney carcinoma cell line A498 (ATCC: HTB-44), U-2 OS (ATCC: HTB-96) and primary cultures of normal nasal mucosal epithelia (NNM). Primary cultures of NNM were generated from biopsies of patients with nasal polyposis $(34,35)$. The use of NNM was approved by the Human Subject Research Ethics Committee, Institutional Review Board, Academia Sinica (AS-IRB01-06008). Human umbilical vein endothelial cells (HUVECs) were purchased (Lonza, Walkersville, MD, USA) and cultured in EBM-2 media (Lonza). The human oral cancer cell line SAS was obtained from the Japanese Collection of Research Bioresources (Tokyo, Japan). The cells were cultivated in Dulbecco's modified Eagle's media (DMEM) supplemented with $10 \%$ fetal bovine serum (FBS), at $37^{\circ} \mathrm{C}$ with $5 \% \mathrm{CO}_{2}$. Other cell lines were purchased from ATCC and were cultured in Dulbecco's modified Eagle's media (DMEM) supplemented with 5 or $10 \%$ FBS (Gibco, Grand Island, NY, USA), at $37^{\circ} \mathrm{C}$ in a humidified incubator containing $5 \% \mathrm{CO}_{2}$. Cells were cultured in accordance with protocols obtained from the ATCC and were passaged for fewer than 6 months after resuscitation.

Generation of monoclonal antibodies and purification of IgG. Monoclonal antibodies against human cancer cells were generated following a standard procedure (36), with slight modifications $(37,38)$. Briefly, female BALB/cJ mice [4-6-week-old; National Laboratory Animal Center (NLAC), Taipei, Taiwan] were immunized intraperitoneally with SAS four times at 3-week intervals. On day 4 after the final boost, splenocytes were harvested from the immunized mouse spleen and fused with NSI/1-Ag4-1 myeloma cells using 50\% polyethylene glycol (Gibco). Fused cells were suspended in DMEM supplemented with hypoxanthine-aminopterinthymidine (HAT; Sigma, St. Louis, MO, USA) and hybridoma cloning factor (ICN Biomedicals, Aurora, OH, USA) and were then plated onto 96-well plates. These hybridomas, which were positive for SAS but negative for NNM, were then subcloned by limited dilution, before being preserved in liquid nitrogen.
Ascites were produced in pristane-primed BALB/cJ mice, and mAbs were purified using a protein $\mathrm{G}$ Sepharose $4 \mathrm{G}$ gel (GE Healthcare Biosciences, Pittsburgh, PA, USA).

ELISA. Cell culture (96-well) plates (Corning Costar, St. Louis, MO, USA) were seeded with SAS, NPC, H441, HCT116, SKOV-3, MCF7, BxPC-3, NNM or HUVECs cells. The plates were fixed with $2 \%$ paraformaldehyde, and blocked with $1 \%$ bovine serum albumin (BSA). OCAb9-1 was added to the plates, which were then incubated for $1 \mathrm{~h}$. The plates were subsequently washed with PBS containing $0.1 \%(\mathrm{w} / \mathrm{v})$ Tween-20 $\left(\mathrm{PBST}_{0.1}\right)$, followed by incubation with horseradish peroxidase-conjugated anti-mouse IgG (115-035-062; Jackson ImmunoResearch Laboratories, West Grove, PA, USA) for $1 \mathrm{~h}$. After washing, the plates were incubated with substrate solution (o-phenylenediamine dihydrochloride; Sigma, P6787). The reaction was stopped by the addition of $3 \mathrm{~N} \mathrm{HCl}$, and signals were detected using a microplate reader at $490 \mathrm{~nm}$.

Flow cytometry. SAS, HCT116 and NNM cells were dissociated with $0.25 \%$ trypsin-EDTA $(1 \mathrm{mM})$ (Invitrogen) for 1-3 min. Cells were washed with cell sorting buffer (PBS containing $1 \%$ fetal calf serum) and then incubated for $1 \mathrm{~h}$ at $4^{\circ} \mathrm{C}$ in cell sorting buffer with OCAb9-1 at dilutions ranging from 0.00001 to $1 \mu \mathrm{g} / \mathrm{ml}$. Cells were then incubated with phycoerythrin (PE)-conjugated goat anti-mouse IgG (dilution 1:250; 111-166-144; Jackson ImmunoResearch Laboratories) for $30 \mathrm{~min}$ at $4^{\circ} \mathrm{C}$. After a final wash, the cells were re-suspended with $1 \%$ FBS in PBS and analyzed by flow cytometry (BD Biosciences, San Jose, CA, USA).

Immunofluorescent staining. Cells cultured on coverslips were fixed in $2 \%$ paraformaldehyde for $20 \mathrm{~min}$ before being washed, and subsequently blocked with $1 \%$ BSA in PBS for $30 \mathrm{~min}$. Cells were incubated at room temperature (RT) with OCAb9-1 $(1 \mu \mathrm{g} / \mathrm{ml})$ in $1 \% \mathrm{BSA}$ for $1 \mathrm{~h}$. The cover slide was incubated with Alexa Fluor 488 goat anti-mouse antibodies (Invitrogen) for $1 \mathrm{~h}$ at RT. Nuclei were counterstained with 4',6-diamidino2-phenylindole (DAPI 1:500). The fluorescent images were observed under a fluorescent microscope (A-Zeiss).

Identification of the target protein. SAS cells were lysed with lysis buffer [50 mM Tris-HCl, pH 7.4, $150 \mathrm{mM} \mathrm{NaCl}, 1 \%$ Nonidet P-40 (NP-40)] supplemented with a protease inhibitor cocktail tablet (Roche Diagnostics, Indianapolis, IN, USA). The supernatant was applied to protein $\mathrm{G}$ sepharose (GE Healthcare Biosciences) coupled to OCAb9-1. After washing, the proteins bound to OCAb9-1 were eluted with elution buffer (0.2 $\mathrm{M}$ glycine, $\mathrm{pH} 2.5,150 \mathrm{mM} \mathrm{NaCl}$ and $1 \% \mathrm{NP}-40)$, and the eluates were neutralized with $1 \mathrm{M}$ Tris- $\mathrm{HCl}, \mathrm{pH} 9.1$ (37). The eluates were then separated by SDS-PAGE. The band of interest was cut from the gel, reduced with $50 \mathrm{mM}$ dithioerythritol (DTE) in $25 \mathrm{mM}$ ammonium bicarbonate (ABC) at $\mathrm{pH} 8.5$ for $1 \mathrm{~h}$ at $37^{\circ} \mathrm{C}$, and alkylated with $100 \mathrm{mM}$ iodoacetamide (IAA) in $\mathrm{ABC}$ for $1 \mathrm{~h}$ at RT. After washing with $50 \%$ acetonitrile in $\mathrm{ABC}$, the gel was soaked in $100 \%$ acetonitrile and incubated with $0.02 \mu \mathrm{g}$ trypsin for $16 \mathrm{~h}$ at $37^{\circ} \mathrm{C}$. The digested peptides were extracted with $50 \%$ acetonitrile in 5\% TFA, and concentrated using a Concentrator (Eppendorf, Hamburg, Germany). The sample was subjected to LC-MS/MS sequencing, as 
performed by the Core Facility for Proteomics and Structural Biology Research at Academia Sinica.

Lentivirus production. Small hairpin RNA vectors for EpCAM silencing (5'-GCAAATGGACACAAATTACAA-3'; 5'-GCC GTAAACTGCTTTGTGAAT-3') were obtained from the National RNAi Core Facility (Academia Sinica, Taiwan). To generate stable EpCAM-knockdown cell lines, HEK293T packaging cells were co-transfected with a packaging plasmid (pCMV- $\Delta$ R8.91), and envelope (pMDG) and hairpin pLKORNAi vectors using a PolyJet Transfection kit (SignaGen Laboratories, Ijamsville, MD, USA). At 48-h post-transfection, virus-containing supernatants were collected, mixed with fresh media containing polybrene $(8 \mu \mathrm{g} / \mathrm{ml})$ and incubated with target cells for another $48 \mathrm{~h}$. Transduced cells were selected with puromycin $(2 \mu \mathrm{g} / \mathrm{ml})$ for 7 days.

Immunohistochemistry and evaluation of EpCAM expression. EpCAM expression was detected by immunohistochemistry using the murine mAb OCAb9-1. Tumor tissues from human tissue arrays (Pantomics Inc., San Franscico, CA, USA) were incubated with the mAb OCAb9-1 at a concentration of $1 \mu \mathrm{g} / \mathrm{ml}$ for $1 \mathrm{~h}$ at RT. After being washed with $\mathrm{PBST}_{0.1}$, sections were treated with the polymerbased Super Sensitive IHC detection system (BioGenex, San Ramon, CA, USA). In brief, sections were incubated with Super Enhancer reagent for $20 \mathrm{~min}$ at RT and were then thoroughly rinsed three times with $\mathrm{PBST}_{0.1}$ for $5 \mathrm{~min}$ each. Sections were subsequently treated with Poly-HRP reagent for $30 \mathrm{~min}$ at RT. Diaminobenzidine hydrochloride (DAB) $(0.02 \%)$ containing $0.03 \% \mathrm{H}_{2} \mathrm{O}_{2}$ was used as a chromogen to visualize peroxidase activity. The preparations were lightly counterstained with hematoxylin, mounted with Permount (Fisher Scientific, Pittsburgh, PA, USA) and examined by light microscopy. A human cancer tissue microarray (TMA MTU391 or TMA COC961) was purchased from Pantomics, Inc., and expression of EpCAM was analyzed using HistoQuest software (TissueGnostics, Vienna, Austria). Human cancer tissue microarrays (TMAs) were purchased from Biomax. The use of TMAs was approved by the Human Subject Research Ethics Committee, Institutional Review Board, Academia Sinica (AS-IRB02100067). EpCAM overexpression was defined by calculating a total staining score as the product of a proportion score (0-3) and an intensity score (0-3). The proportion score indicated the estimated fraction of positively-stained tumor cells $(0,<10 \%$; $1,<10-30 \% ; 2,30-50 \% ; 3,>50 \%$ ), while the intensity score indicated the estimated staining intensity ( 0 , no staining; 1 , weak; 2 , moderate; 3 , strong). The total score ranged from zero to nine. Samples were divided into two groups based on their EpCAM total score: group 1, low level expression (score $<3$ ); group 2, high level expression (previously described as overexpression, score $\geq 3$ ) (39).

Immunoprecipitation and western blot analysis. Cells were extracted with RIPA buffer [0.01 M sodium phosphate (pH 7.2), $150 \mathrm{mM} \mathrm{NaCl}, 2$ mM EDTA, $50 \mathrm{mM} \mathrm{NaF}, 1 \%$ NP-40, $1 \%$ sodium deoxycholate, and $0.1 \%$ SDS] supplemented with a protease inhibitor mixture tablet (Roche Diagnostics) and centrifuged at $20,000 \times \mathrm{g}$ for $30 \mathrm{~min}$ at $4^{\circ} \mathrm{C}$. An equal amount of proteins $(1 \mathrm{mg})$ were incubated with Dynabeads protein $\mathrm{G}$
(Invitrogen Dynal AS, Oslo, Norway) conjugated to OCAb9-1 antibody $(3 \mu \mathrm{g})$ at $4^{\circ} \mathrm{C}$ for $4 \mathrm{~h}$. The mixtures were washed twice with ice-cold RIPA buffer and boiled in SDS-sample buffer. For western blotting, cells were extracted using RIPA buffer containing protease inhibitor cocktail (Roche, Basel, Switzerland). Equal amounts of protein were separated on SDS-PAGE and then transferred to PVDF membranes (Millipore, Bedford, MA, USA). The membrane was blocked with $1 \%$ BSA, and incubated with OCAb9-1 (1 $\mu \mathrm{g} / \mathrm{ml})$, antiEpCAM mAb (1:100 dilution; 1144-1; Epitomics, Burlingame, CA, USA), anti-p53 (0.1 $\mu \mathrm{g} / \mathrm{ml}$; OP43L; Calbiochem, Merck KGaA, Darmstadt, Germany), anti-p21 Waf1/Cip1 (1:1000 dilution; \#2946; Cell Signaling Technology, Inc. Danvers, MA, USA), or $\alpha$-tubulin (1:5000; Sigma) mAbs overnight. Membranes were then incubated with HRP-conjugated secondary antibodies (1:10,000; Jackson ImmunoResearch) for $1 \mathrm{~h}$ at room temperature, and protein expression was detected using an ECL kit (Millipore, Temecula, CA, USA).

$R N A$ extraction and quantitative real-time $R T-P C R$. Total RNA samples were prepared from cell lines using Ultraspec RNA isolation reagent (Biotecx Laboratories, Inc., Houston, TX, USA). RNA was reverse transcribed into cDNA using SuperScript III RNase $\mathrm{H}$ reverse transcriptase (Invitrogen, Carlsbad, CA, USA), according to the manufacturer's instructions. The forward and reverse primers for PCR are listed in Table I. Quantitative RT-PCR was performed using the LightCycler 480 II system (Roche Applied Science, Indianapolis, IN, USA). Expression levels of each gene were normalized to the expression level of GAPDH in the same sample. The reactions were performed in triplicate, and SD values were calculated.

Surface plasmon resonance. The affinities of murine antibodies were determined by surface plasmon resonance (Biacore T200; Biacore). EpCAM antigen was immobilized on a Series S Sensor Chip CM5 (Biacore) and injected at a flow rate of $10 \mu \mathrm{l} / \mathrm{min}$. The $\mathrm{mAb}$ were diluted in HBS-EP buffer (Biacore) and injected at a flow rate of $30 \mu \mathrm{l} / \mathrm{min}$ for $1.5 \mathrm{~min}$; $\mathrm{mAb}$ were then allowed to dissociate over $5 \mathrm{~min}$. Before injection of each $\mathrm{mAb}$, the surface was regenerated by injection of a solution of $10 \mathrm{mM}$ glycine $\mathrm{HCl}, 0.2 \mathrm{M} \mathrm{NaCl}$ (pH 2.5). The data were analyzed using BIAevaluation software with a global fit 1:1 binding model.

Animal model of colon carcinoma metastasis. The NOD/SCID mice were obtained from Jackson Laboratory (Bar Harbor, ME, USA) and were bred in the core facility of ICOB in Acdemia Sinica. HCT116 cells $\left(1 \times 10^{6}\right.$ cells/mouse) were injected into 6 -week-old female NOD/SCID mice through the lateral tail vein. Mice were then treated with PBS and OCAb9-1. The dosage was $20 \mathrm{mg} / \mathrm{kg}$ on days 1 and 4 . Mouse body weight and survival rate were measured twice a week $(n=8)$. Mice were monitored every day and given soft diet to decrease the suffering of the mice. For mouse survival study, the tumor size was not appropriate to use as a humane endpoint. Alternatively, we used humane endpoints by judgment of the mouse weight loss ( $>20 \%$ of body weight) or mouse activity assessment (hunching, stationary, ruffling and poor grooming). Animal care was carried out according to guidelines established by 
Table I. Primers used for cloning and quantitative RT-PCR.

\begin{tabular}{|c|c|c|}
\hline Assay & Gene & Sequence $\left(5^{\prime}-3^{\prime}\right)$ \\
\hline \multirow[t]{2}{*}{ Q-RT-PCR } & EpCAM & $\begin{array}{l}\text { F: aatgtgtgtgcgtggga } \\
\text { R: ttcaagattggtaaagccagt }\end{array}$ \\
\hline & $G A P D H$ & $\begin{array}{l}\text { F: cttcaccaccatggaggaggc } \\
\text { R: ggcatggactgtggtcatgag }\end{array}$ \\
\hline \multirow[t]{6}{*}{ ChIP } & EpCAM (-630 to -550$)$ & $\begin{array}{l}\text { F: acatcttcaagtgctagaaatgc } \\
\text { R: gaaatcttggctctcttggg }\end{array}$ \\
\hline & EpCAM (-354 to -273$)$ & $\begin{array}{l}\text { F: ccattcttcaaggcttcagag } \\
\text { R: ggcgttagggatctttggt }\end{array}$ \\
\hline & EpCAM (+426 to +539$)$ & $\begin{array}{l}\text { F: cctcacttcgcagctttg } \\
\text { R: gccgcaggaaacctgga }\end{array}$ \\
\hline & EpCAM (+835 to +967$)$ & $\begin{array}{l}\text { F: gcttattgtagggaacgcag } \\
\text { R: cgacagagcaagactcag }\end{array}$ \\
\hline & $H B B$ & $\begin{array}{l}\text { F: atctgagccaagtagaagaccttttc } \\
\text { R: tctgcctggactaatctgcaag }\end{array}$ \\
\hline & $G A P D H$ & $\begin{array}{l}\text { F: tccaagcgtgtaagggt } \\
\text { R: gaagggactgagattggc }\end{array}$ \\
\hline \multirow[t]{2}{*}{ MSP } & EpCAM-methylated & $\begin{array}{l}\text { F: tttaacgtcgttatggagacga } \\
\text { R: gctaatactcgttaataaatcaccg }\end{array}$ \\
\hline & EpCAM-unmethylated & $\begin{array}{l}\text { F: tttaatgttgttatggagatga } \\
\text { R: accactaatactcattaataaatcaccac }\end{array}$ \\
\hline Bisulfite sequencing & EpCAM & $\begin{array}{l}\text { F: aaggaagttttagtatagaatttttaaat } \\
\text { R: aaaaaaataaataaactcccctcc }\end{array}$ \\
\hline
\end{tabular}

F, forward; R, reverse.

Academia Sinica, Taiwan. The protocol was approved by the Committee on the Ethics of Animal Experiments of Academia Sinica (AS IACUC: 11-04-166).

Genomic DNA isolation, bisulfite modification and methylation specific PCR (MSP). The $\mathrm{CpG}$ methylation status of the EpCAM promoter was evaluated by MSP. Genomic DNA was purified using the Wizard Genomic DNA purification kit (Promega, Madison, WI, USA). The bisulfite reaction was performed on $500 \mathrm{ng}$ DNA, which was further subjected to bisulfite modification using the EZ DNA methylation kit, according to the manufacturer's directions (Zymo Research, Orange, CA, USA). The primers used for MSP amplification are listed in Table I. PCRs were performed in a thermocycler (Bio-Rad Laboratories, Richmond, CA, USA) for 40 cycles at $95^{\circ} \mathrm{C}$ for $1 \mathrm{sec}, 51^{\circ} \mathrm{C}$ for $5 \mathrm{sec}$, and $72^{\circ} \mathrm{C}$ for $25 \mathrm{sec}$, followed by a final extension at $72^{\circ} \mathrm{C}$ for $10 \mathrm{sec}$ to amplify bisulfitemodified DNA.

Bisulfite sequencing. Genomic DNA (500 ng) was treated with the EZ DNA modification kit (Zymo Research), according to the manufacturer's recommendations. Completely methylated and unmethylated control genomic DNAs were purchased from Qiagen (Valencia, CA, USA). The promoter regions of the $E p C A M$ gene were amplified by PCR. Primer sequences used for PCR amplification are listed in Table I. The PCR products were purified using the QIAquick PCR purification kit (Qiagen), following the manufacturer's instructions. The purified PCR products were then subcloned into a TA cloning vector (pGEM-T Easy vector; Promega). Clones (twenty for control DNA and ten for each sample) were verified by sequencing with the T7 universal primer.

Chromatin immunoprecipitation (ChIP) and quantitative real-time $P C R$. ChIP was performed as previously described (40) with some modifications. Briefly, ChIP assays were carried out on $1 \times 10^{5}$ HCT116 and NNM cells. The protein-DNA complexes were fixed using $1 \%$ formaldehyde, and the cross-linking reaction was quenched by adding glycine to a final concentration of $200 \mathrm{mM}$. The chromatin complexes were then sonicated to an average size of $250 \mathrm{bp}$ using a Misonix Sonicator 3000. Protein A beads (Invitrogen) were incubated at $4^{\circ} \mathrm{C}$ for $2 \mathrm{~h}$ with one of the following antibodies: anti-H3K4me3 (2.4 $\mu \mathrm{g}$; ab8580; Abcam, Cambridge, MA, USA), anti-H3K9K14Ac (2.4 $\mu \mathrm{g}$; 06-599; Upstate-Millipore, Charlottesville, VA, USA), anti-H3K27me3 (5 $\mu \mathrm{g}$; ab6002; Abcam), anti-H3K9me3 (5 $\mu \mathrm{g}$; 07-442; Upstate), anti-SUZ12 (2 $\mu \mathrm{g}$; ab12073; Abcam) or anti-JMJD3 (4 $\mu \mathrm{g}$; AP1022a; Abgent, San Diego, CA, USA). The antibodies were subsequently incubated with chromatin for a further $2 \mathrm{~h}$. The bound 


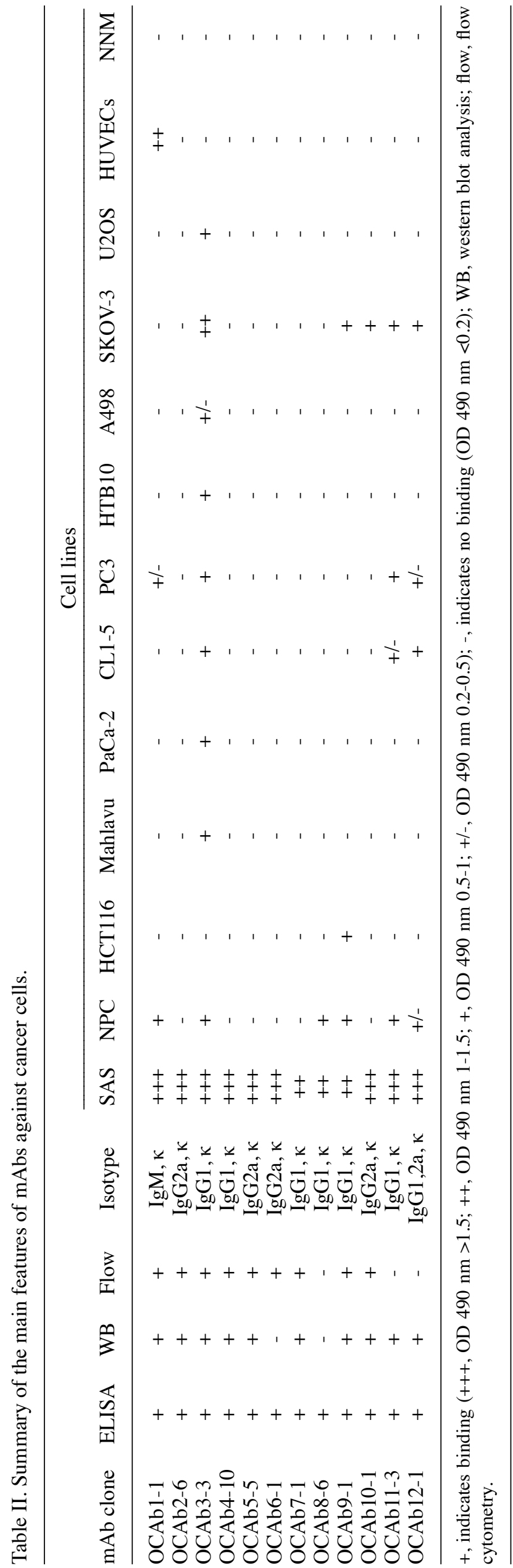

Table III. Expression of OCAb9-1 target in colon carcinoma.

\begin{tabular}{|c|c|c|c|}
\hline & \multirow[b]{2}{*}{$\mathrm{n}$} & \multicolumn{2}{|c|}{$\begin{array}{l}\text { OCAb9-1 target } \\
\text { expression }\end{array}$} \\
\hline & & Low (\%) & High (\%) \\
\hline Normal colon & 5 & 100 & 0 \\
\hline \multicolumn{4}{|c|}{$\begin{array}{l}\text { Colorectal carcinoma } \\
\text { Invasion depth }\end{array}$} \\
\hline $\mathrm{T} 1$ & 1 & 100 & 0 \\
\hline $\mathrm{T} 2$ & 18 & 22.2 & 77.8 \\
\hline $\mathrm{T} 3$ & 14 & 42.86 & 57.14 \\
\hline \multicolumn{4}{|l|}{ Tumor grade } \\
\hline I & 12 & 16.7 & 83.3 \\
\hline II & 13 & 38.5 & 61.5 \\
\hline III & 3 & 66.7 & 33.3 \\
\hline
\end{tabular}

fraction was isolated using Protein A beads according to the manufacturer's instructions, and the immunocomplexes were subsequently subjected to reverse crosslinking. The immunoprecipitated DNA was recovered using a PCR purification kit (Qiagen) according to the manufacturer's instructions, and target DNA was detected by real-time PCR using the LightCycler 480 System (Roche). The amplification primers are listed in Table I. For each sample, PCR analysis was performed in triplicate, and the bound fraction was compared with input DNA from $1 \times 10^{4}$ cells. For each gene, the ratio of immunoprecipitated DNA to input DNA (IP/Input) was determined. To obtain relative occupancy values, the IP/Input was further normalized to the level observed at a control region, $H B B$ (H3K4me3, H3K9K14Ac and SUZ12) or GAPDH (H3K27me3, H3K9me3, JMJD3 and EpCAM), which was defined as 1.0 .

Statistical analysis. All data were derived from at least three independent experiments. Values are expressed as the mean \pm SD. Experimental test conditions were compared with the respective control by Student's t-test, unless otherwise specified. Differences were considered significant at ${ }^{*} \mathrm{P}<0.05$, ${ }^{* *} \mathrm{P}<0.01$ or ${ }^{* * *} \mathrm{P}<0.001$. Survival analyses were performed using Kaplan-Meier survival curves, and significant differences between groups were tested using the log-rank test. Correlation coefficients were assayed by Spearman's analysis.

\section{Results}

Generation and characterization of $m A$ Abs recognizing cancer cells. We generated more than 8,000 hybridoma clones, twelve clones exhibiting relatively high reactivity against SAS cells were selected (Table II). Cellular ELISA and western blotting revealed that OCAb9-1 specifically recognized several human cancer cells (SAS, NPC, HCT116, H441, MCF7, BxPC-3 and SKOV-3), but not normal cells, such as NNM or HUVECs (Fig. 1A and B). Closer examination by immunofluorescent analysis (Fig. 1C) and FACS (Fig. 1D) revealed that this $\mathrm{mAb}$ exhibited extremely high cell surface binding activity for 
A

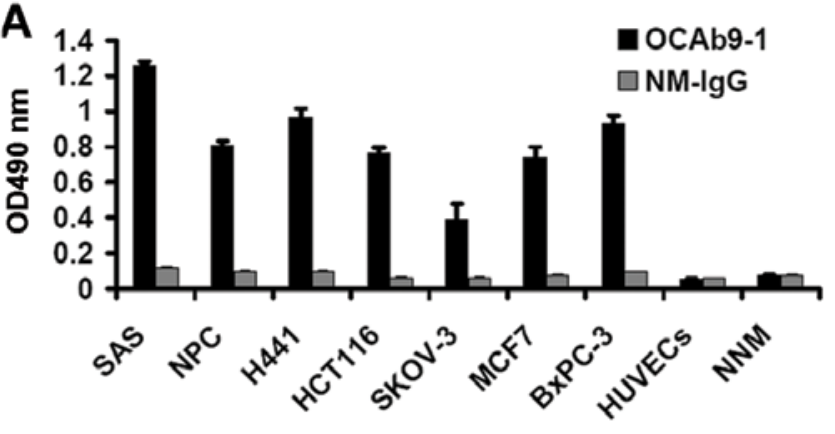

Cell lines
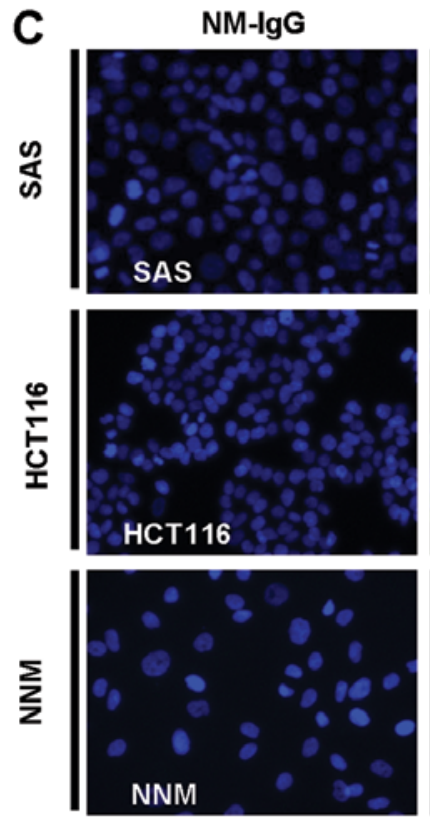

B

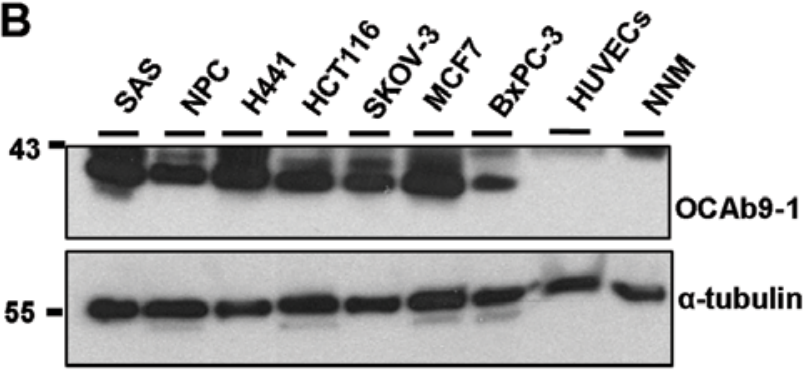

D

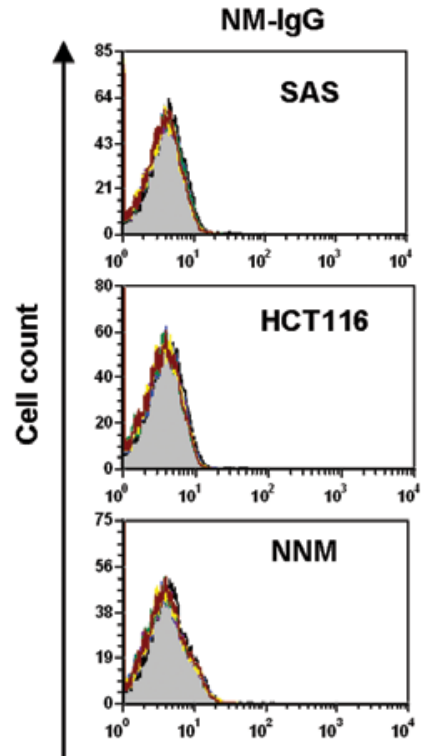

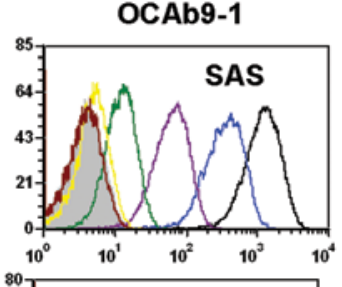

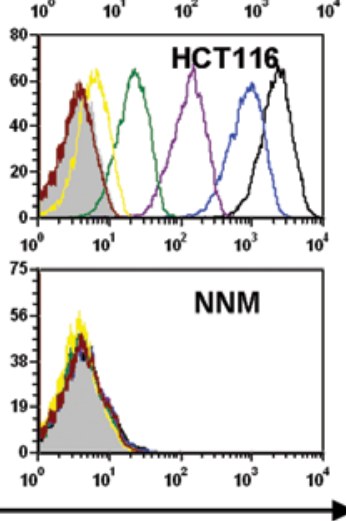

Fluorescence intensity

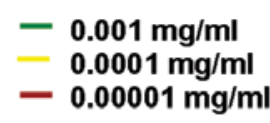

Figure 1. Generation and characterization of mAb recognizing human cancer cells. (A) ELISA analysis of the binding of OCAb9-1 to various cancer cell lines NM-IgG (normal mouse IgG) was used as a control. Error bars indicate the mean \pm SD; n=3; OD490 nm, optical density at 490 nm. (B) Western blotting of OCAb9-1 against the indicated cell lines. OCAb9-1 recognized human cancer cell lines. SAS, HCT116 and NNM cells were incubated with OCAb9-1. Binding reactivities of OCAb9-1 mAb were measured by (C) immunofluorescent staining and (D) flow cytometry.

SAS and HCT116 cells, but did not bind to NMM cells. The binding affinities of OCAb9-1 are summarized in Table II. Further experiments using various human cancer tissue arrays confirmed that OCAb9-1 was able to specifically recognize human cancer tissues of different origins including oral, colon, ovarian, breast, pancreatic and uterus cancer, but not matched normal tissues (Fig. 2A). Thirty-three samples of colon adenocarcinoma tissue specimens from a colon cancer tissue array stained positively for OCAb9-1, while five normal colon tissues showed little staining (Fig. 2B and Table III). All 33 patients in a colon cancer microarray were analyzed, and most of these samples exhibited intense OCAb9-1 staining in the majority of tumor cells (Table III).

To identify the target molecule of OCAb9-1,SAS cell lysates were prepared and purified by OCAb9-1-conjugated immunoaffinity chromatography. Silver staining and western blotting
Table IV. Kinetic constants and binding affinities of antiEpCAM mAbs.

\begin{tabular}{lccc}
\hline mAb colon & $\mathrm{K}_{\mathrm{d}}(\mathrm{M})$ & $\mathrm{K}_{\text {on }}\left(\mathrm{M}^{-1} \mathrm{~S}^{-1}\right)$ & $\mathrm{K}_{\text {off }}\left(\mathrm{S}^{-1}\right)$ \\
\hline OCAb9-1 & $7.168 \times 10^{-11}$ & $3.284 \times 10^{6}$ & $2.354 \times 10^{-4}$
\end{tabular}

$\mathrm{K}_{\mathrm{on}}$ and $\mathrm{K}_{\text {off }}$ were measured with SRP in a Biacore using purified $\mathrm{mAb}$, and $\mathrm{K}_{\mathrm{d}}$ was calculated with BIAevaluation software.

demonstrated that OCAb9-1 recognized a target protein with a molecular weight of $39 \mathrm{kDa}$ (Fig. 2C). LC-MS/MS was used to identify this protein as human EpCAM (Fig. 2D). The specificity of OCAb9-1 for EpCAM was confirmed by immunoprecipitation assays and western blotting with a commercial 

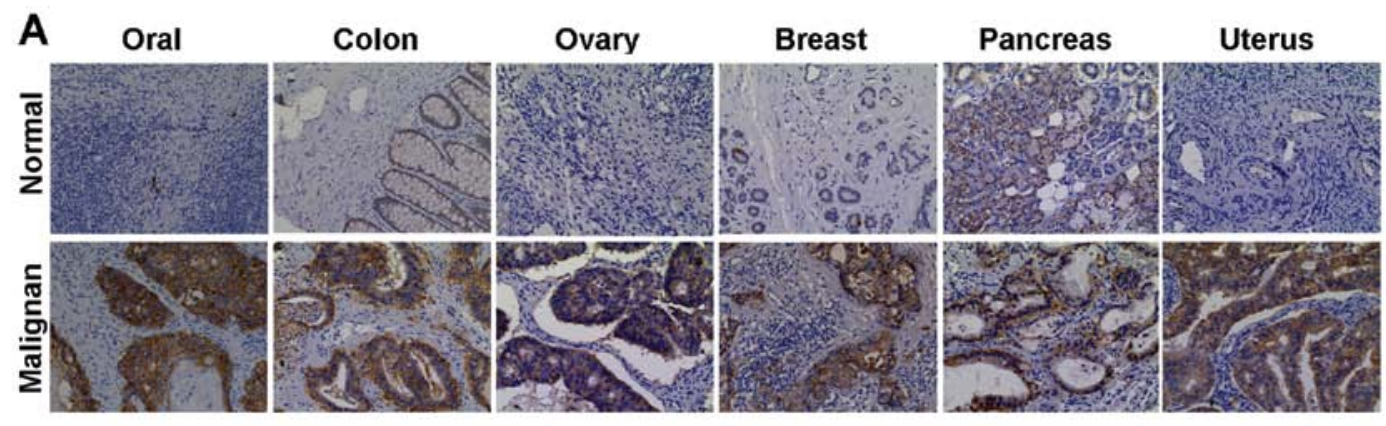

B

Adenocarcinoma

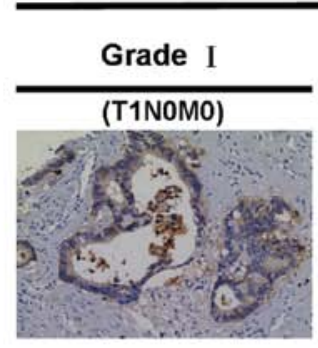

(T2NOMO)

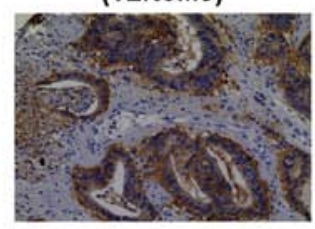

C

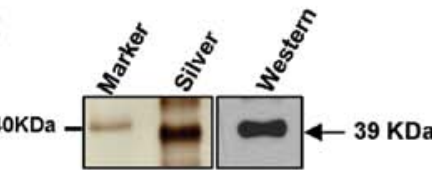

Grade II

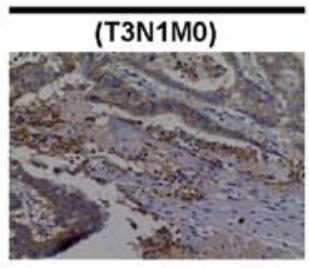

(T3NOMO)

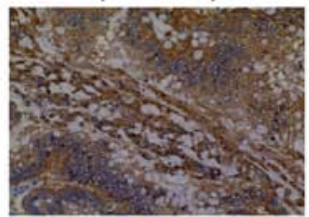

Grade III

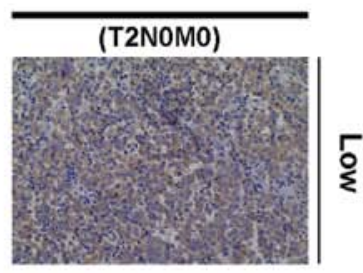

(T3N1M0)

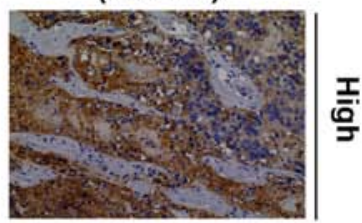

$\mathbf{E}$

동

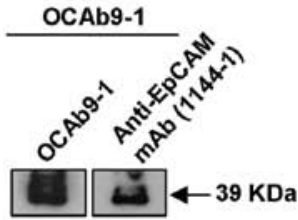

D

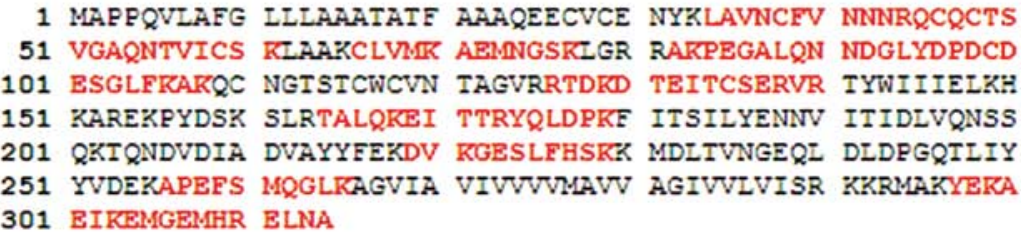

Figure 2. Identification of the binding activity and target protein of OCAb9-1. (A) Immunohistochemical staining of human tissue arrays with OCAb9-1. Paraffin-embedded sections of the indicated human cancer tissues and matched normal tissues were incubated with OCAb9-1. Brown, OCAb9-1 target; blue, hematoxylin (used for background staining). Cell images were acquired at x200 magnification. (B) Immunohistochemical staining of a human colon cancer tissue array with OCAb9-1. Samples were divided into two groups based on their OCAb9-1 target total score: group 1, low level expression (score <3); group 2, high level expression (previously described as overexpression, score $\geq 3$ ). (C) Purification of the protein targeted by OCAb9-1 using immunoaffinity chromatography. Western blotting of purified proteins revealed a 39-kDa protein (indicated by the arrow), which was subjected to LC-MS/MS analyses (D) The Swiss-Prot database was used to identify the 39-kDa protein as EpCAM. Full-length human TACSTD1 (EpCAM) is a 314 amino acid polypeptide. Highlighted sequences indicate the peptides hit by LC-MS/MS. (E) Proteins immunoprecipitated from SAS lysates with OCAb9-1 antibody were subjected to western blot analysis with rabbit anti-EpCAM mAb (1144-1).

rabbit anti-EpCAM antibody, 1144-1 (Fig. 2E). OCAb9-1 has a very high affinity for EpCAM, with a kinetic constant of 71.68 pM (Table IV).

Inhibition of cancer cell growth in vitro by EpCAM shRNA. The functional role of EpCAM in tumorigenesis was evaluated by knocking down its expression in SAS cells with EpCAM shRNA (Fig. 3A). Western blotting (Fig. 3B) and FACS (Fig. 3C) revealed a dramatic decrease in OCAb9-1 after
EpCAM knockdown, thereby confirming the specificity of OCAb9-1 against EpCAM. Knockdown of EpCAM also suppressed growth rate (Fig. 3D), colony formation (Fig. 3E), migration (Fig. 3F) and the invasion ability (Fig. 3G) of SAS tumor cells. We next examined whether knockdown of EpCAM affected the expression of the $p 53$ and $p 21$ genes in SAS cells. Western blotting revealed that the p53 and p21 proteins were increased following EpCAM knockdown (Fig. 3H), confirming earlier findings (41). In summary, EpCAM knockdown inhibits 
A

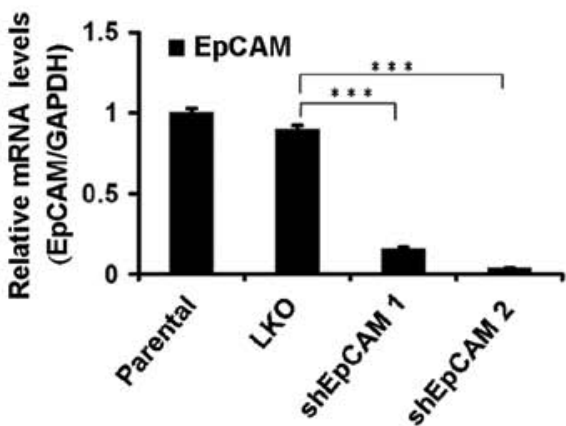

D

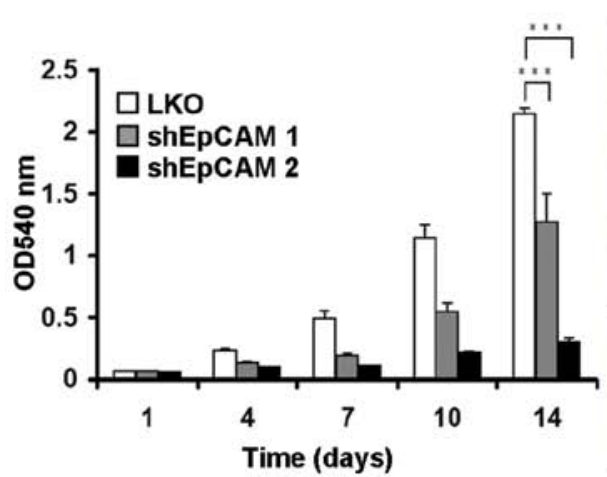

B

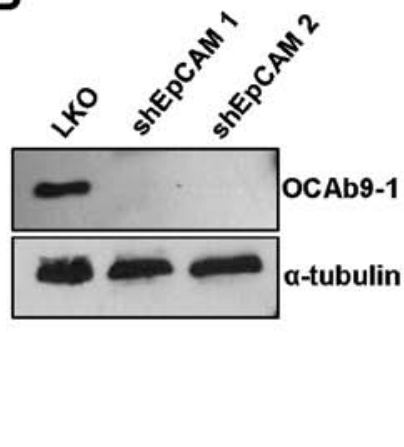

\section{LKO - ShEpCAM 1 \\ - shEpCAM 2}

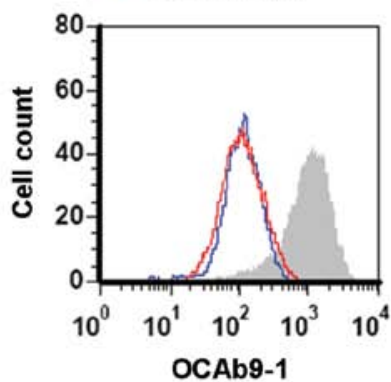

E

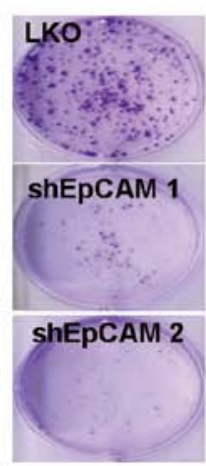

F
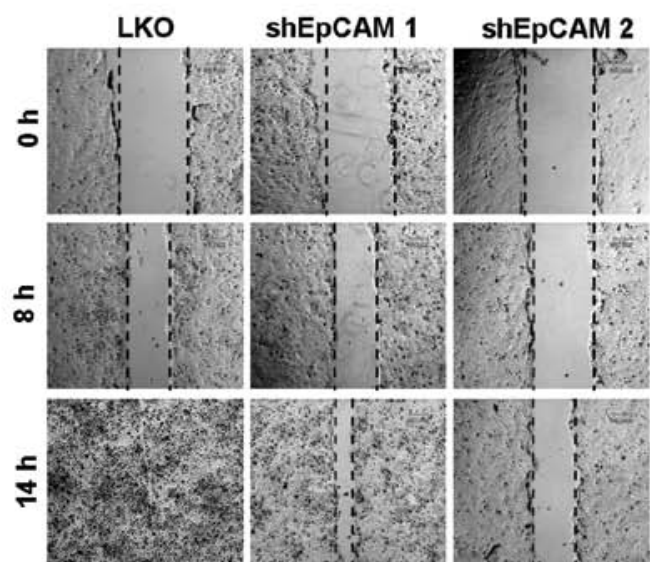

G
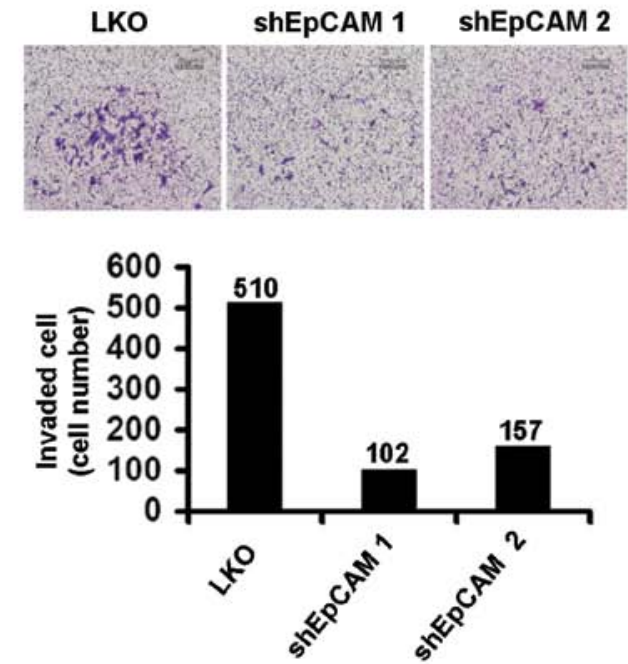

H

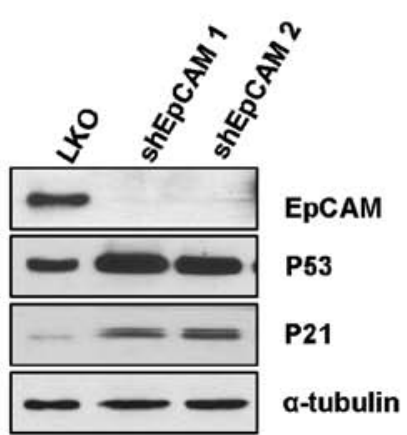

Figure 3. EpCAM regulates cancer cell growth and motility. (A) SAS cells were transfected with one of two EpCAM shRNA plasmids (shEpCAM 1 and shEpCAM 2). Examination of total RNA by q-RT-PCR analysis revealed a clear suppressive effect of shEpCAM on $E p C A M$ mRNA expression in transfected cells. RNA samples from multiple cells were mixed, and each value represents the mean $\pm \mathrm{SD}(\mathrm{n}=3)$; ${ }^{* * *} \mathrm{P}<0.001$. $(\mathrm{B}) \mathrm{Western}$ blot analysis and $(\mathrm{C})$ flow cytometric analyses were performed to evaluate OCAb9-1 binding to EpCAM-knockdown SAS and mock cells. (D) Downregulation of EpCAM inhibited cell proliferation in SAS cells. Cell viability was determined by MTT assay. (Student's t-test, ${ }^{* *} \mathrm{P}<0.01,{ }^{* * * *} \mathrm{P}<0.001$.) (E-G) Suppression of EpCAM inhibited colony formation (E), migration (F), and invasion $(\mathrm{G})$ of tumor cells in vitro. $(\mathrm{H})$ Knockdown of EpCAM upregulates expression of p53 and p21.

cancer cell growth, migration and invasion, and upregulates pro-apoptotic gene expression in vitro. These results suggest that EpCAM may be a potential target for cancer therapy.

EpCAM methylation status in HCT116 and NNM. It remains unclear why EpCAM is overexpressed in HCT116 cells, more insights in the epigenetic regulation of the EpCAM gene promoter itself are required. Accessibility of transcription factors to the specific binding sites within the EpCAM gene depends on the chromatin structure, which is affected by DNA methylation and histone modifications (42). We examined the methylation status of EPCAM promoter regions in both 

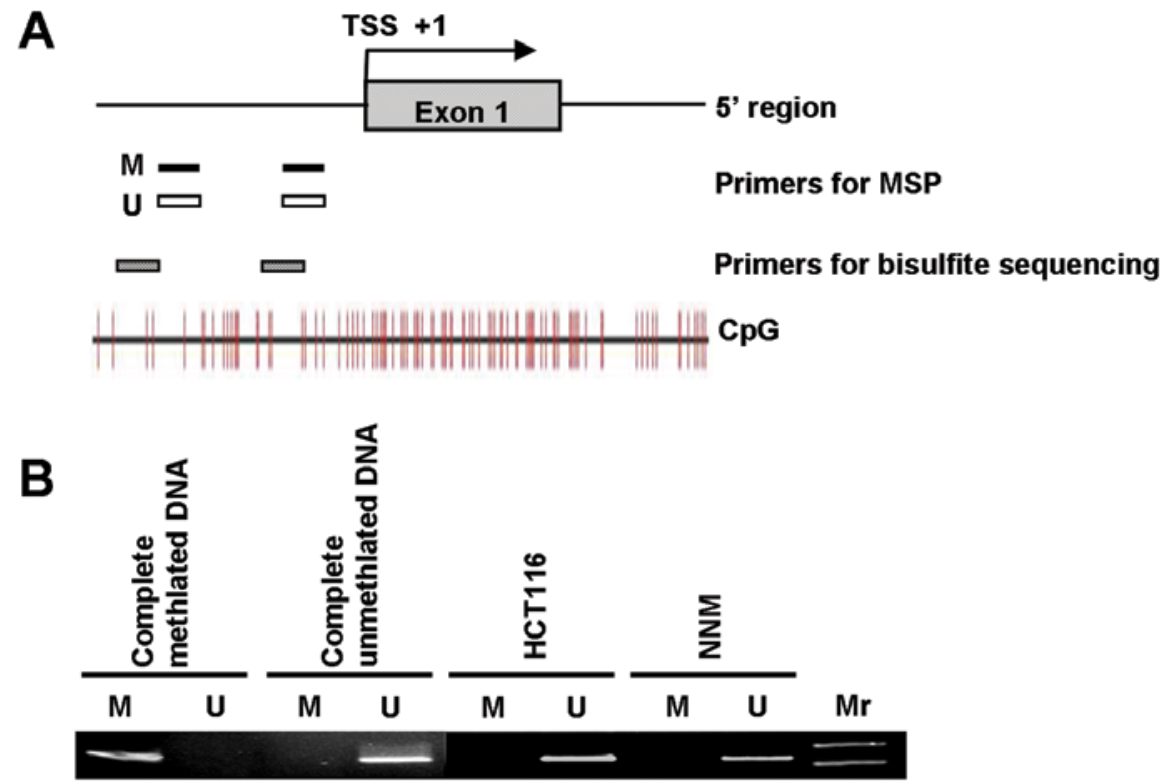

C

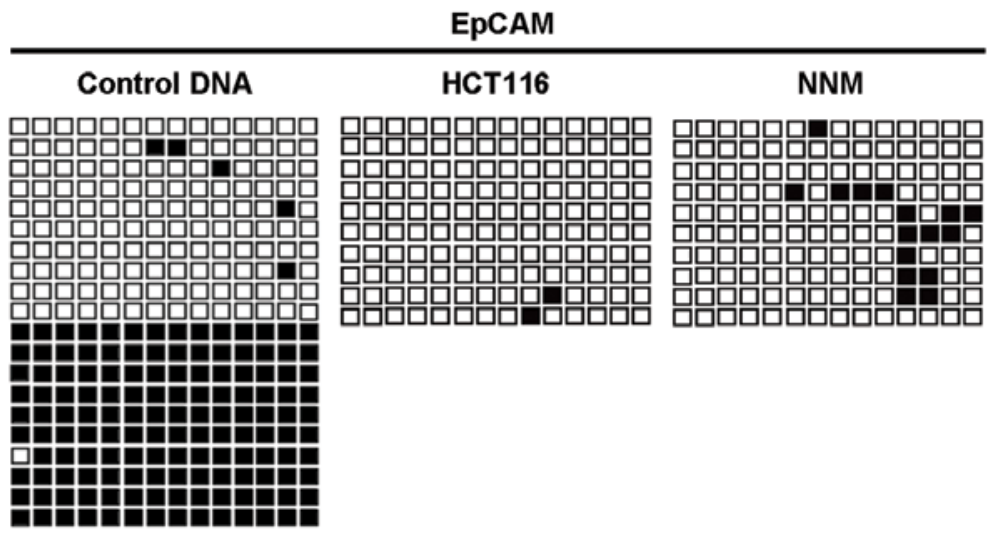

Figure 4. Methylation status of EpCAM promoter regions in HCT116 and NNM cells. (A) Schematic depiction of the EpCAM upstream region. Primers for MSP and bisulfite sequencing are indicated. (B) MSP analysis of the EpCAM gene promoter region in HCT116 and NNM cells. M (methylated) indicates PCR products generated by methylation-specific primers, and U (unmethylated) indicates those generated by primers specific for unmethylated DNA. (C) Mapping the methylation status of the $\mathrm{CpG}$ islands in the EPCAM promoter region by bisulfite sequencing. Open squares represent unmethylated cytosines; filled squares represent methylated cytosines. Most CpGs in the promoter region were ummethylated in both HCT116 and NNM cells.

HCT116 and NNM to determine whether EpCAM expression correlates with DNA methylation. Fig. 4A depicts the gene structure and $\mathrm{CpG}$ content of the EpCAM promoter region. Primers for MSP and bisulfite sequencing were designed to target the 5' flanking region of the EpCAM promoter. MSP assays were performed to determine the methylation status of EpCAM for both HCT116 and NNM. We used commercially available completely methylated and completely unmethylated DNAs as controls for the primers. As shown in Fig. 4B, PCR using primers against unmethylated sequences amplified DNA from both HCT116 and NNM cells, whereas PCR using primers against methylated sequences resulted in trace amounts of DNA from NNM cells only.

To further determine the $\mathrm{CpG}$ island methylation status of the EpCAM gene promoter in HCT116 and NNM cells, we used bisulfite-assisted genomic sequencing. Clone sequencing analysis revealed that $98 \%$ of the $\mathrm{CpG}$ sites of the HCT116 clones and $84 \%$ of those of the NNM clones are unmethyl- ated (Fig. 4C). These results indicate that EpCAM silencing in NMM may not be due to changes in the methylation status of the EpCAM promoter in these cells.

Histone modification of the EPCAM promoter region in HCT116 and NNM. To address whether there is an association between EpCAM expression and chromatin architecture in cancer cells, we examined the histone modification profile of the region encompassing the EpCAM promoter in HCT116 and NNM cells. To this end, we performed ChIP assays against four histone modifications (lysine 4 trimethylation of histone 3 (H3K4me3), lysine 9/14 acetylation of histone 3 (H3K9K14Ac), lysine 27 trimethylation of histone 3 (H3K27me3), and lysine 9 trimethylation of histone $3(\mathrm{H} 3 \mathrm{~K} 9 \mathrm{me} 3))$ at four regions of the EpCAM promoter: upstream distal (-630 to -550$)$ and proximal $(-354$ to -273$)$, and downstream proximal $(+426$ to +539$)$ and distal $(+835$ to +967$)$ relative to the transcription start site (TSS). 


\section{EpCAM}

\section{$\square$ : Untranslated Region (UTR) $\square$ : Protein Coding Sequence (CDS)}

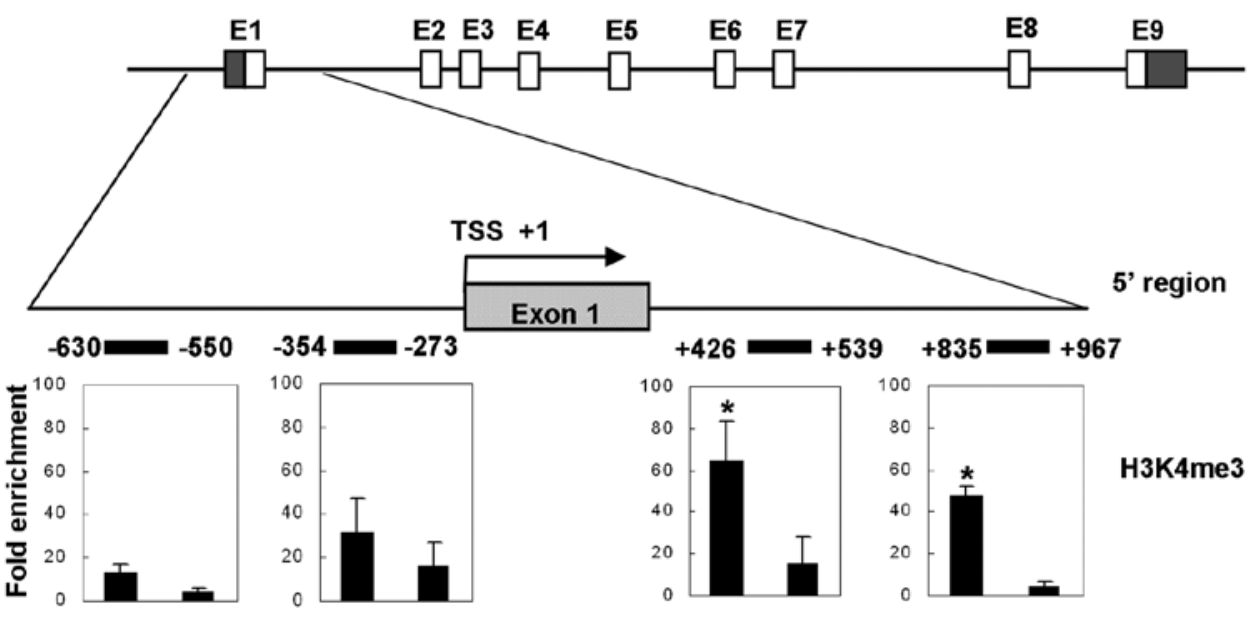

B
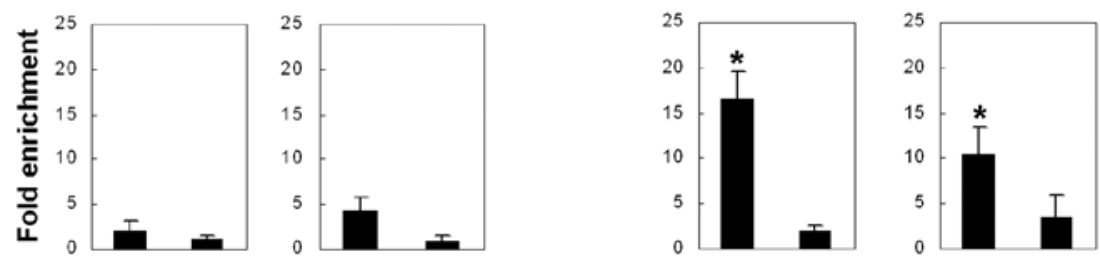

H3K9K 14AC

C

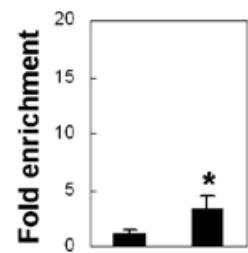

D

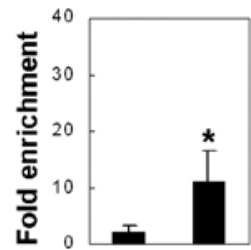

E

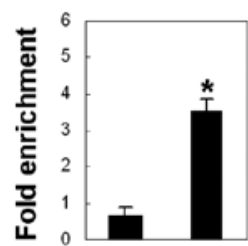

$\mathbf{F}$

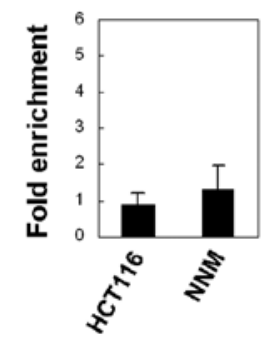

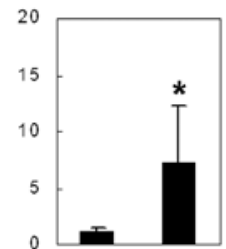
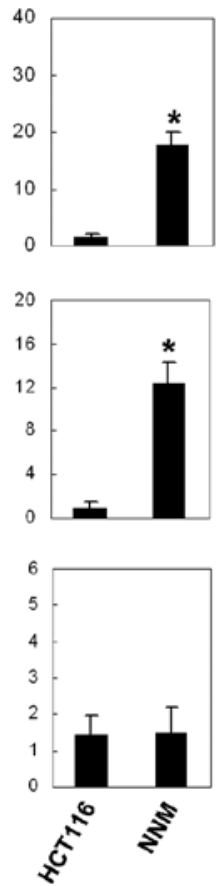
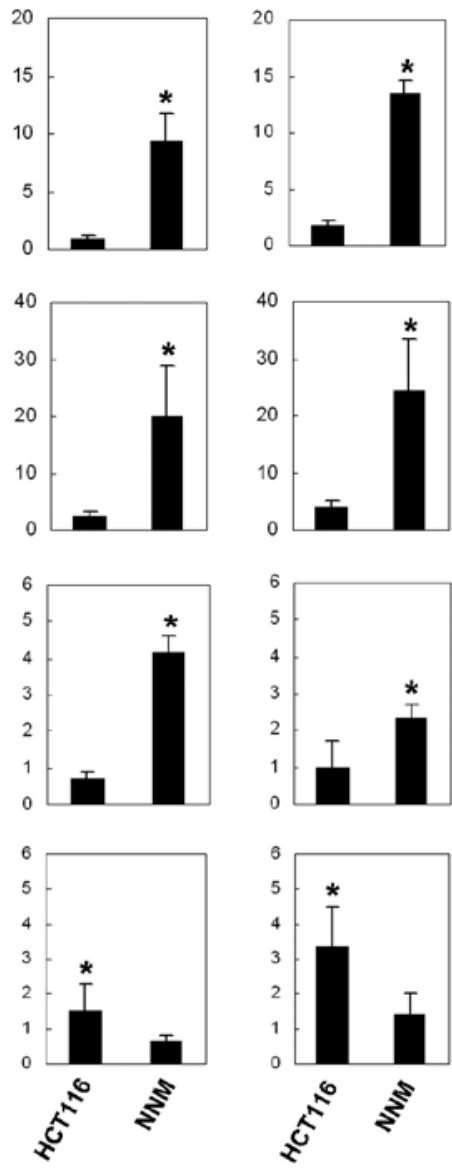

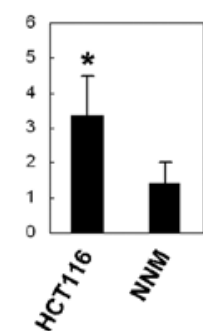

H3K9me3

SUZ12

H3K27me3

Hok

JMJD3

Figure 5. Histone mark distribution and recruitment of chromatin modifiers to the EpCAM promoter in HCT116 and NNM cells. Top. Schematic depiction of the EPCAM gene promoter region. The nucleotide numbers represent the distances from the TSS $(+1)$. The positions of the ChIP primers used are indicated as horizontal lines. (A-D) ChIP followed by q-PCR analyses showing quantitative occupancy of H3K4me3 (A), H3K9K14Ac (B), H3K27me3 (C) and H3K9me3 (D) at the EpCAM promoter in HCT116 and NNM cells. (E and F) Chromatin samples were immunoprecipitated with anti-SUZ12 antibody (E) or anti-JMJD3 antibody (F), and enrichment at the EPCAM and KRT1 promoter was quantitated by Q-PCR. KRT1 was used as a reference for SUZ12/JMJD3 binding. Each experiment was performed in triplicate (data are presented as the mean $\pm \mathrm{SD}$ ). The amount of immunoprecipitated DNA was calculated as the ratio of IP DNA to the total amount of input DNA used for the immunoprecipitation (IP/Input). To obtain relative fold enrichment values, the target IP/Input was further normalized to the level of a control promoter region of $H B B$ (H3K4me3, H3K9K14Ac) or of GAPDH (H3K27me3, H3K9me3); ${ }^{*} \mathrm{P}<0.05$. 


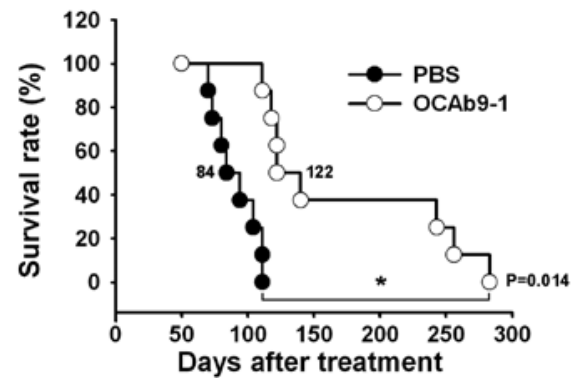

Figure 6. OCAb9-1 enhances survival in an animal model of tumor metastasis. NOD/SCID mice were intravenously injected with $1 \times 10^{6}$ HCT116 cells, and then twice with either PBS or OCAb9-1 $(20 \mathrm{mg} / \mathrm{kg})(\mathrm{n}=8)$. The survival curves indicate that mice treated with OCAb9-1 exhibited a greater survival rate than equivalents treated with $\mathrm{PBS}$

In HCT116 cells, H3K4me3 occupancy was enhanced at both proximal and distal regions downstream of TSS, but unaffected at proximal and distal regions upstream of TSS, as compared to that in NNM cells (Fig. 5A). H3K9K14Ac association has been reported to be enriched at the $5^{\prime}$ end of active genes, and to be strongly correlated with $\mathrm{H} 3 \mathrm{~K} 4 \mathrm{me} 3$ (43). Consistent with these earlier findings, the acetylation level of H3K9K14 was high in both proximal and distal downstream regions of TSS in EpCAM-positive HCT116, as observed for H3K4me3 (Fig. 5B).

Previous studies have suggested that there is a correlation between H3K27me3 and gene repression (44). Indeed, our study found H3K27me3 signals to be elevated at all upstream and downstream regions of the silent EpCAM promoter of NNM cells (Fig. 5C). Methylation of lysine 9 of histone 3 is known to facilitate formation of heterochromatin, and elevated levels of $\mathrm{H} 3 \mathrm{~K} 9 \mathrm{me} 3$ at promoter sequences have been associated with suppression of gene expression $(44,45)$. We observed enhanced $\mathrm{H} 3 \mathrm{~K} 9 \mathrm{me} 3$ occupancy at all four promoter regions in NNM as compared to HCT116 cells (Fig. 5D). Our profiling of histone modifications by ChIP suggests that chromatin remodeling in the 5' flanking region of the $E p C A M$ promoter may be responsible for the increase in EpCAM expression in HCT116 colon cancer cells.

We subsequently investigated whether recruitment of the polycomb protein SUZ12 underlies the increased methylation of $\mathrm{H} 3 \mathrm{~K} 27$ at the EpCAM promoter in NNM cells. As hypothesized, we detected higher SUZ12 signals in NNM than in HCT116 cells, both upstream and downstream of the EpCAM promoter (Fig. 5E). These results suggest that EpCAM is controlled by the PRC2 complex, the major histone methyltransferase responsible for H3K27me3. Conversely, we observed a corresponding rise in JMJD3 binding at both proximal and distal regions downstream of the EpCAM TSS in HCT116 cells (Fig. 5F), which coincided with the reduction of H3K27me3 (Fig. 5C); this suggests a direct causal relationship between JMJD3 recruitment and H3K27 demethylation. These findings indicate that EpCAM expression in HCT116 cells is maintained by the loss of H3K27me3 and SUZ12 at the promoter of the EPCAM gene, and this is accompanied by an increase in JMJD3.

OCAb9-1 increases the survival rate of an animal model of colon cancer metastasis. The OCAb9-1 exhibited high speci- ficity against EpCAM in colorectal cancer tissue (Fig. 2B), we then proceeded to use OCAb9-1 in an animal model of colon carcinoma metastasis to investigate whether targeting EpCAM can prolong the survival of tumor-bearing mice. NOD/SCID mice were injected intravenously with HCT116 cells; mice bearing circulating HCT116 cells were intravenously treated with OCAb9-1 or an equivalent volume of PBS at 24 and $96 \mathrm{~h}$ after cell injection (antibody was delivered at $20 \mathrm{mg} / \mathrm{kg} /$ dose, for a total dose of $40 \mathrm{mg} / \mathrm{kg}$ ). The median overall survival of tumor-bearing mice treated with OCAb9-1 was significantly higher than that of PBS-treated mice (Fig. 6). The median overall survival of tumor-bearing mice was 122 or 84 days after treatment with OCAb9-1 or PBS, respectively (Fig. 6). The difference in overall survival (OS) between the PBS and OCAb9-1 treatment groups (as determined using Kaplan-Meier curves) was found to be statistically significant (log-rank test; $\mathrm{P}=0.014$ ). The data provided direct evidence demonstrating that by targeting EpCAM can directly increase the median overall survival of metastatic tumor-bearing mice.

\section{Discussion}

The importance of EpCAM expression in tumor-initiating cells (TICs) or cancer stem cells (CSC) has been previously emphasized (46). EpCAM exerts oncogenic effects on members of the wht pathway, accounting for the high expression of EpCAM in many cancers, particularly TICs from various tumor entities $(4,47)$. Colon cancer cells exhibit the highest level of EpCAM expression of any cancer, with the frequency for any subgroup being typically $>90 \%$ (22). Such a frequency of EpCAM enrichment in colorectal cancer at all stages of the disease makes colon cancer an ideal indication for anti-EpCAM-based therapies. Novel human anti-EpCAM or bispecific T-cell engaging antibodies may facilitate the development of an anti-EpCAM-based therapy for the treatment of cancer.

The current standard treatment for stage IV metastatic colorectal cancer involves the use of a combination of chemotherapeutic agents, including irinotecan, fluorouracil, and leucovorin (IFL), following surgical resection (48). In stage III colon cancer, adjuvant therapy with edrecolomab plus fluorouracil-based therapy did not have a statistically significant effect on the overall survival of patients (49). Adecatumumab (MT201), which is a fully human IgG1 mAb targeting EpCAM, has activity independent of K-Ras status. A phase II study in patients with metastatic breast cancer confirmed the overall safety and feasibility of single-agent treatment with adecatumumab (21). Despite effective adjuvant treatment, many patients experience disease recurrence and death from disseminated disease. Thus, there is a need for more effective adjuvant treatments for colon cancer. We previously generated a novel antibody, OCAb9-1, which has been shown to exhibit high specificity to EpCAM. To evaluate the therapeutic efficacy of OCAb9-1 as a potential treatment for colon cancer, we treated human colon cancer with the antibody in metastatic animal models (Fig. 6). The metastatic colon cancer-bearing mice treated with OCAb9-1 exhibited markedly prolonged median overall survival, indicating the significant therapeutic potential of the antibody. 
The expression of EpCAM has been used to recognize hepatic stem cells in fetal, postnatal and adult humans (13-15), and is believed to be useful in the selection of tumor-initiating cells $(11,12)$. Normal pancreatic tissues also express EpCAM (Fig. 2A), accounting for the pancreatitis observed in certain clinical trials of anti-EpCAM based therapeutics $(50,51)$. In our previous study, we found that EpCAM signaling triggered by the release of extracellular domain of EpCAM (EpEX) and intracellular domain of EpCAM (EpICD) is observed in cancer cells, but not in normal healthy cells (52). Hence, it is possible that pancreatitis may be avoided by novel therapeutic antibody that triggers cancer cell apoptosis by inhibiting EpCAM signaling (52) without affecting EpCAM function in healthy pancreatic cells.

Post-translational modifications (including phosphorylation, acetylation, ubiquitination and methylation) of histone tails have been confirmed to be dynamic regulators of gene expression. The polycomb group ( $\mathrm{PcG}$ ) proteins are important chromatin modifiers that play a pivotal role in the epigenetic regulation of the development, differentiation, and maintenance of cell fates (53). Polycomb repressive complex 2 (PRC2) mediates transcriptional repression by catalyzing the tri-methylation of lysine 27 on histone H3 (H3K27me3) (54). Suppressor of Zeste 12 homolog (SUZ12) is essential for methylation of $\mathrm{H} 3 \mathrm{~K} 27 \mathrm{me} 3$ by PRC2 (55-57). The recent identification of the JmjC-domain-containing histone lysine demethylase JMJD3 suggests that there may be positive and negative regulators simultaneously controlling chromatin structure dynamics through histone methylation. JMJD3 specifically removes trimethyl marks from H3K27 in mammalian cells to antagonize PcG gene silencing and permit gene transcription $(58,59)$. These findings suggest that EpCAM may be regulated by both SUZ12 and JMJD3 during tumor progression. Our investigation into the epigenetic regulation of EpCAM in HCT116 cells indicates that the expression of EpCAM was not regulated by DNA methylation, a process that irreversibly silences genes (Fig. 4). Instead, we found that there is a drastic reduction in histone active markers, namely H3K4 trimethylation and $\mathrm{H} 3 \mathrm{~K} 9$ acetylation, and a clear enhancement of repressive markers, $\mathrm{H} 3 \mathrm{~K} 9$ and $\mathrm{H} 3 \mathrm{~K} 27$ trimethylation, at the EpCAM promoter in NNM cells (Fig. 5). Our results suggest that the dynamic expression pattern of EpCAM during tumor progression is carefully modulated by histone modifying enzymes, such as SUZ12 and JMJD3, but not by DNA methylase; as a consequence, plasticity of EpCAM expression is maintained.

\section{Acknowledgements}

We thank the Core Facility of the Institute of Cellular and Organismic Biology, and the RNAi core Facility of the Institute of Molecular Biology, Academia Sinica, for technical support. This research was supported by grants from Academia Sinica and the National Science Council (NSC102-2325-B-001-010 and NSC102-2321-B-001-021), Taiwan (to H-C.W.).

\section{References}

1. Peto J: Cancer epidemiology in the last century and the next decade. Nature 411: 390-395, 2001.
2. Jemal A, Bray F, Center MM, et al: Global cancer statistics. CA Cancer J Clin 61: 69-90, 2011.

3. van der Gun BT, Melchers LJ, Ruiters MH, et al: EpCAM in carcinogenesis: the good, the bad or the ugly. Carcinogenesis 31: 1913-1921, 2010.

4. Visvader JE and Lindeman GJ: Cancer stem cells in solid tumours: accumulating evidence and unresolved questions. Nat Rev Cancer 8: 755-768, 2008.

5. Litvinov SV, Velders MP, Bakker HA, et al: a human epithelial antigen is a homophilic cell-cell adhesion molecule. J Cell Biol 125: 437-446, 1994.

6. Litvinov SV, Balzar M, Winter MJ, et al: Epithelial cell adhesion molecule (Ep-CAM) modulates cell-cell interactions mediated by classic cadherins. J Cell Biol 139: 1337-1348, 1997.

7. Balzar M, Prins FA, Bakker HA, et al: The structural analysis of adhesions mediated by Ep-CAM. Exp Cell Res 246: 108-121, 1999.

8. de Boer CJ, van Krieken JH, Janssen-van Rhijn CM, et al: Expression of Ep-CAM in normal, regenerating, metaplastic, and neoplastic liver. J Pathol 188: 201-206, 1999.

9. Litvinov SV, van Driel W, van Rhijn CM, et al: Expression of Ep-CAM in cervical squamous epithelia correlates with an increased proliferation and the disappearance of markers for terminal differentiation. Am J Pathol 148: 865-875, 1996.

10. Maetzel D, Denzel S, Mack B, et al: Nuclear signalling by tumour-associated antigen EpCAM. Nat Cell Biol 11: 162-171, 2009.

11. Al-Hajj M, Wicha MS, Benito-Hernandez A, et al: Prospective identification of tumorigenic breast cancer cells. Proc Natl Acad Sci USA 100: 3983-3988, 2003.

12. Dalerba P, Dylla SJ, Park IK, et al: Phenotypic characterization of human colorectal cancer stem cells. Proc Natl Acad Sci USA 104: 10158-10163, 2007.

13. Schmelzer E, Wauthier E and Reid LM: The phenotypes of pluripotent human hepatic progenitors. Stem Cells 24: 1852-1858, 2006.

14. Dan YY, Riehle KJ, Lazaro C, et al: Isolation of multipotent progenitor cells from human fetal liver capable of differentiating into liver and mesenchymal lineages. Proc Natl Acad Sci USA 103: 9912-9917, 2006.

15. Schmelzer E, Zhang L, Bruce A, et al: Human hepatic stem cells from fetal and postnatal donors. J Exp Med 204: 1973-1987, 2007.

16. Anderson R, Schaible K, Heasman J, et al: Expression of the homophilic adhesion molecule, Ep-CAM, in the mammalian germ line. J Reprod Fertil 116: 379-384, 1999.

17. Stingl J, Raouf A, Emerman JT, et al: Epithelial progenitors in the normal human mammary gland. J Mammary Gland Biol Neoplasia 10: 49-59, 2005.

18. Moldenhauer G, Salnikov AV, Luttgau S, et al: Therapeutic potential of amanitin-conjugated anti-epithelial cell adhesion molecule monoclonal antibody against pancreatic carcinoma. J Natl Cancer Inst 104: 622-634, 2012.

19. Simon M, Stefan N, Pluckthun A, et al: Epithelial cell adhesion molecule-targeted drug delivery for cancer therapy. Expert Opin Drug Deliv 10: 451-468, 2013.

20. Punt CJ, Nagy A, Douillard JY, et al: Edrecolomab alone or in combination with fluorouracil and folinic acid in the adjuvant treatment of stage III colon cancer: a randomised study. Lancet 360: 671-677, 2002.

21. Schmidt M, Scheulen ME, Dittrich C, et al: An open-label, randomized phase II study of adecatumumab, a fully human antiEpCAM antibody, as monotherapy in patients with metastatic breast cancer. Ann Oncol 21: 275-282, 2010.

22. Went P, Vasei M, Bubendorf L, et al: Frequent high-level expression of the immunotherapeutic target Ep-CAM in colon, stomach, prostate and lung cancers. Br J Cancer 94: 128-135, 2006.

23. MacDonald GC, Rasamoelisolo M, Entwistle J, et al: A phase I clinical study of VB4-845: weekly intratumoral administration of an anti-EpCAM recombinant fusion protein in patients with squamous cell carcinoma of the head and neck. Drug Des Devel Ther 2: 105-114, 2009.

24. Migliore L, Migheli F, Spisni R, et al: Genetics, cytogenetics, and epigenetics of colorectal cancer. J Biomed Biotechnol 2011: 792362, 2011.

25. Coppede F: Epigenetic biomarkers of colorectal cancer: focus on DNA methylation. Cancer Lett 342: 238-247, 2014.

26. Tai KY, Shiah SG, Shieh YS, et al: DNA methylation and histone modification regulate silencing of epithelial cell adhesion molecule for tumor invasion and progression. Oncogene 26: 3989-3997, 2007. 
27. Spizzo G, Gastl G, Obrist P, et al: Methylation status of the Ep-CAM promoter region in human breast cancer cell lines and breast cancer tissue. Cancer Lett 246: 253-261, 2007.

28. Yu G, Zhang X, Wang $\mathrm{H}$, et al: $\mathrm{CpG}$ island methylation status in the EpCAM promoter region and gene expression. Oncol Rep 20: 1061-1067, 2008.

29. Shiah SG, Chang LC, Tai KY, et al: The involvement of promoter methylation and DNA methyltransferase-1 in the regulation of EpCAM expression in oral squamous cell carcinoma. Oral Oncol 45: e1-8, 2009.

30. van der Gun BT, Wasserkort R, Monami A, et al: Persistent downregulation of the pancarcinoma-associated epithelial cell adhesion molecule via active intranuclear methylation. Int J Cancer 123: 484-489, 2008.

31. Heyn $\mathrm{H}$ and Esteller M: DNA methylation profiling in the clinic: applications and challenges. Nat Rev Genet 13: 679-692, 2012.

32. Lin CT, Chan WY, Chen W, et al: Characterization of seven newly established nasopharyngeal carcinoma cell lines. Lab Invest 68: 716-727, 1993.

33. Oefinger PE, Bronson DL and Dreesman GR: Induction of hepatitis B surface antigen in human hepatoma-derived cell lines. J Gen Virol 53: 105-113, 1981.

34. Lo A, Lin CT and Wu HC: Hepatocellular carcinoma cellspecific peptide ligand for targeted drug delivery. Mol Cancer Ther 7: 579-589, 2008.

35. Lee TY, Wu HC, Tseng YL, et al: A novel peptide specifically binding to nasopharyngeal carcinoma for targeted drug delivery. Cancer Res 64: 8002-8008, 2004.

36. Kohler G and Milstein C: Continuous cultures of fused cells secreting antibody of predefined specificity. Nature 256: 495-497, 1975.

37. Liu IJ, Chiu CY, Chen YC, et al: Molecular mimicry of human endothelial cell antigen by autoantibodies to nonstructural protein 1 of dengue virus. J Biol Chem 286: 9726-9736, 2011.

38. Tung KH, Lin CW, Kuo CC, et al: CHC promotes tumor growth and angiogenesis through regulation of HIF-1alpha and VEGF signaling. Cancer Lett 331: 58-67, 2013.

39. Spizzo G, Went P, Dirnhofer S, et al: High Ep-CAM expression is associated with poor prognosis in node-positive breast cancer. Breast Cancer Res Treat 86: 207-213, 2004.

40. Lu TY, Kao CF, Lin CT, et al: DNA methylation and histone modification regulate silencing of OPG during tumor progression. J Cell Biochem 108: 315-325, 2009.

41. Huang HP, Chen PH, Yu CY, et al: Epithelial cell adhesion molecule (EpCAM) complex proteins promote transcription factor-mediated pluripotency reprogramming. J Biol Chem 286: 33520-33532, 2011.

42. Esteller M: Epigenetics in cancer. N Engl J Med 358: 1148-1159, 2008.

43. Bernstein BE, Kamal M, Lindblad-Toh K, et al: Genomic maps and comparative analysis of histone modifications in human and mouse. Cell 120: 169-181, 2005.
44. Barski A, Cuddapah S, Cui K, et al: High-resolution profiling of histone methylations in the human genome. Cell 129: 823-837, 2007.

45. Mutskov V and Felsenfeld G: Silencing of transgene transcription precedes methylation of promoter DNA and histone $\mathrm{H} 3$ lysine 9. EMBO J 23: 138-149, 2004.

46. Munz M, Baeuerle PA and Gires O: The emerging role of EpCAM in cancer and stem cell signaling. Cancer Res 69: 5627-5629, 2009.

47. Gires O, Klein CA and Baeuerle PA: On the abundance of EpCAM on cancer stem cells. Nat Rev Cancer 9: 143; author reply $143,2009$.

48. Saltz LB, Cox JV, Blanke C, et al: Irinotecan plus fluorouracil and leucovorin for metastatic colorectal cancer. Irinotecan Study Group. N Engl J Med 343: 905-914, 2000.

49. Fields AL, Keller A, Schwartzberg L, et al: Adjuvant therapy with the monoclonal antibody Edrecolomab plus fluorouracilbased therapy does not improve overall survival of patients with stage III colon cancer. J Clin Oncol 27: 1941-1947, 2009.

50. de Bono JS, Tolcher AW, Forero A, et al: ING-1, a monoclonal antibody targeting Ep-CAM in patients with advanced adenocarcinomas. Clin Cancer Res 10: 7555-7565, 2004.

51. Goel S, Bauer RJ, Desai K, et al: Pharmacokinetic and safety study of subcutaneously administered weekly ING-1, a human engineere monoclonal antibody targeting human EpCAM, in patients with advanced solid tumors. Ann Oncol 18: 1704-1707, 2007.

52. Lin CW, Liao MY, Lin WW, et al: Epithelial cell adhesion molecule regulates tumor initiation and tumorigenesis via activating reprogramming factors and epithelial-mesenchymal transition gene expression in colon cancer. J Biol Chem 287: 39449-39459, 2012.

53. Schuettengruber $\mathrm{B}$, Chourrout $\mathrm{D}$, Vervoort $\mathrm{M}$, et al: Genome regulation by polycomb and trithorax proteins. Cell 128: 735-745, 2007.

54. Schwartz YB and Pirrotta V: Polycomb silencing mechanisms and the management of genomic programmes. Nat Rev Genet 8: 9-22, 2007

55. Cao R and Zhang Y: SUZ12 is required for both the histone methyltransferase activity and the silencing function of the EED-EZH2 complex. Mol Cell 15: 57-67, 2004.

56. Pasini D, Bracken AP, Jensen MR, et al: Suz12 is essential for mouse development and for EZH2 histone methyltransferase activity. EMBO J 23: 4061-4071, 2004.

57. Swigut T and Wysocka J: H3K27 demethylases, at long last. Cell 131: 29-32, 2007

58. Agger K, Cloos PA, Christensen J, et al: UTX and JMJD3 are histone H3K27 demethylases involved in HOX gene regulation and development. Nature 449: 731-734, 2007.

59. Boyer LA, Plath K, Zeitlinger J, et al: Polycomb complexes repress developmental regulators in murine embryonic stem cells. Nature 441: 349-353, 2006 